\title{
Simultaneous Recovery of Rare Earths and Uranium from Wet Process Phosphoric Acid using solvent extraction with D2EHPA
}

Shengxi $\mathrm{Wu}^{\mathbf{a}, \mathbf{b}, \mathbf{c}, \mathbf{d}}$, Liangshi Wang ${ }^{\mathbf{a}^{*}}$, Patrick Zhang ${ }^{\mathbf{b}}$, Hassan El-Shall ${ }^{\mathbf{c}}$, Brij

Moudgil $^{\mathrm{c}}$, Xiaowei Huang ${ }^{\mathrm{a}}$, Longsheng Zhao ${ }^{\mathrm{a}}$, Lifeng Zhang ${ }^{\mathrm{d}}$, Zongyu Feng ${ }^{\mathrm{a}}$

${ }^{a}$ National Engineering Research Center for Rare Earth Materials, General Research Institute for Nonferrous Metals, Beijing, 100088, P.R. China

${ }^{b}$ Florida Industrial And Phosphate Research Institute, Bartow, FL, USA

${ }^{c}$ Particle Engineering Research Center, Department of Materials Science and Engineering, University of Florida, Gainesville, FL, USA

${ }^{d}$ School of Metallurgical and Ecological Engineering, University of Science and Technology Beijing (USTB), Beijing, P.R. China

Corresponding author:

Liangshi Wang: Tel.: 0086-010-82241180; E-mail: wls1657@163.com

\begin{abstract}
In most cases, wet-process phosphoric acid (WPA) contains trace amount of rare earth elements and uranium, which ultimately enter and accumulate in soil and may cause environmental damages. In order to remove and recover these elements, studies about solvent extraction of heavy rare earth elements (HREEs) and uranium (U) with D2EHPA, selective stripping of HREEs from $\mathrm{U}$, and evaporation precipitation of light rare earth elements (LREEs) were investigated. Extraction efficiency of U from WPA was greatly enhanced, but HREEs extraction were significantly retarded when using the solvent mixture of di- (2-ethylhexyl) phosphoric acid (D2EHPA) and tri-butyl-phosphate (TBP) or tri-octyl-phosphine oxide (TOPO) compared with D2EHPA alone. $89.4 \%$ and $94.2 \%$ accumulative two-stage extraction efficiencies of HREEs and $\mathrm{U}$, respectively, were achieved with 1.0 M D2EHPA alone. And more than 98.1\% HREEs were selectively stripped from loaded D2EHPA with $6.0 \mathrm{M} \mathrm{HCl}$ via three stages. In addition, LREEs were enriched to $1204.3 \mathrm{ug} / \mathrm{g}$ in evaporation sludge during the concentration process of phosphoric acid from $30 \%$ to $50 \% \mathrm{P}_{2} \mathrm{O}_{5}$, and the filtration performance was greatly improved. Based on the studies, an alternative process was developed to recover and group LREEs, HREEs and U during the phosphoric acid production.
\end{abstract}

Keywords: phosphoric acid, rare earth elements, uranium, solvent extraction, selective stripping, evaporation enrichment

\section{Introduction}

The rare earth elements (REEs) are a series of elements with similar physiochemical properties including 15 elements of lanthanides, yttrium and scandium. Applications of REEs have been extended to metallurgy, magnets, ceramics, electronics, chemical, optical, medical, nuclear technologies due to their specific physiochemical properties (Habashi, 2013; Krishnamurthy and Gupta, 2004; Xu, 1995). Much research has focused on exploration of green processes for REEs recovery from REEs-dispersed minerals and secondary resources in order to meet the growing demand of REEs, especially for green 
energy applications such as battery alloys, solar panels, and wind turbines (Apergis and Apergis, 2017; Liu and Li, 2015). Phosphate rock is considered as one of the most promising new resources for REEs. In addition, considerable amount of $U$ is found in phosphate. Generally, phosphate rock contains about $0.05 \%$ REEs and $0.005-0.02 \%$ U on average, and the yearly production of phosphate rock all over the world is about 200 million tons (Hurst and Crouse, 1974; Ragheb, 2010). That means about 100 kt REEs and $10 \mathrm{kt} \mathrm{U}$ are involved in phosphoric acid production. Without recovery, about $90 \% \mathrm{U}$ and about $30 \%$ REEs would enter and accumulate into soil via fertilizers, that may lead to potential threaten to the environment and human health (Krea and Khalaf, 2000; Reddy et al., 2009).

At present, consumption of phosphate rocks is dominated by the dihydrate phosphoric acid process, which decomposes phosphate rock with sulfuric acid to produce wet process phosphoric acid (WPA) and phosphogypsum (PG) (Zhang, 2014):

$$
\mathrm{Ca}_{5} \mathrm{~F}\left(\mathrm{PO}_{4}\right)_{3}+5 \mathrm{H}_{2} \mathrm{SO}_{4}+10 \mathrm{H}_{2} \mathrm{O}=3 \mathrm{H}_{3} \mathrm{PO}_{4}+5 \mathrm{CaSO}_{4} \cdot 2 \mathrm{H}_{2} \mathrm{O} \downarrow+\mathrm{HF} \uparrow
$$

In this process, about 20-30\% REEs and more than 95\% U transferred into WPA. However, the leaching efficiency of REEs up to $75 \%$ was achieved with a specific addictive under optimized conditions (Sivaprakash, 1989; Wang et al., 2010). The concentration of these elements in WPA range from 10 to $1000 \mathrm{ug} / \mathrm{g}$ depends on the composition of phosphate rocks. It was noted that the proportion of heavy rare earth elements (HREEs) in phosphoric acid is higher than that in leaching solution from bastnasite and monazite (Abreu and Morais, 2010; Al-Thyabat and Zhang, 2015a; AlThyabat and Zhang, 2015b). Therefore, from the prospect of resources, it is of great significance to recover the REEs and $U$ from WPA.

Since the 1930s, many processes have been proposed for REEs recovery from WPA including crystallization, precipitation, solvent extraction, and ion exchange methods (Habashi, 1985; Wu, 1983). However, due to the high energy consumption of crystallization (Weterings and Janssen, 1985), the impurities involvement, high reagent consumption and phosphorus loss in precipitation processes (Lokshin et al., 2005; Lokshin et al., 2004; Lokshin et al., 2007; Lokshin et al., 2011), the low efficiency of ion exchange (less than 60\%) (Reddy et al., 2009; Reddy et al., 2010), these methods did not achieved their industrial applications. Solvent extraction was considered as the most promising method since it is possible to simultaneously recover REEs and U (Beltrami et al., 2014). Organic phosphorus extractants are widely used for REEs and U extraction from WPA. Bunus et al. (Bunus and Dumitrescu, 1992; Bunus et al., 1994; Bunus, 2000) extracted REEs and U with the mixture of D2EHPA+TBP and D2EHPA+TOPO, and stripped REEs and U into green cake with hydrofluoric acid. Krea et al. (Krea and Khalaf, 2000) demonstrated that solvent mixture of di- (octyl phenyl) phosphoric acid (DOPPA)+TOPO did not show significant synergistic effect on REEs and U extraction from WPA under the optimum conditions. Pilot plant tests conducted by Solvay illustrated that mixture of D2EHPA+TOPO could not efficiently extract REEs under the conditions for $U$ extraction (Rollat, 2016). In all these cases, both REEs and U were enriched in the green cake, but the separation of REEs from $U$ required a complex process including acid decomposition, selective extraction, neutralization precipitation 
and further treatments. Furthermore, the extraction process of REEs with solvent mixtures were not deeply understood.

In order to solve these challenges, this study investigated the simultaneous extraction of HREEs and $U$ from WPA with D2EHPA, mixture of D2EHPA+TBP and D2EHPA+TOPO, selective stripping of HREEs from loaded D2EHPA. Behaviors of LREEs during the evaporation process of phosphoric acid from $30 \%$ to $54 \% \mathrm{P}_{2} \mathrm{O}_{5}$ was also studied. Finally, an alternative process was proposed to recover and group HREEs, U and LREEs during the phosphoric acid production.

\section{Experimental}

\subsection{Materials and chemicals}

The di- (2-ethyl hexyl) phosphoric acid with a purity of 95\%, tri-n-butyl-phosphate with a purity of $98 \%$ and kerosene were provided by Alfa Aesar. Tri-n-octyl-phosphine oxide with a purity of $90 \%$ was supplied by Strem Chemicals. Inc. (the structure formula were shown in Tab.2). All other chemicals used were of analytical reagent grade.

The phosphoric acid (brown acid) is produced by dihydrate process from Florida phosphate rock. Before solvent extraction, phosphoric acid needed to go through the following pretreatments (to obtain green acid):

- Using activated carbon to remove organic matters;

- $\quad$ Filtrating through 2-3 cm of bentonite and filter paper to remove suspended particles and organic matters adsorbed on the activated carbon;

Chemical analysis result of acid solution before and after pretreatment were shown in Tab. 1 and the $\mathrm{pH}$ value of green acid is 0.65 .

Tab.1 Chemical analysis of WPA solution before and after pretreatment

\begin{tabular}{cccccccccccc}
\hline Element & $\mathrm{La}$ & $\mathrm{Ce}$ & $\mathrm{Pr}$ & $\mathrm{Nd}$ & $\mathrm{Sm}$ & $\mathrm{Eu}$ & $\mathrm{Gd}$ & $\mathrm{Tb}$ & $\% \mathrm{P}_{2} \mathrm{O}_{5}$ & $\% \mathrm{MgO}$ & $\% \mathrm{CaO}$ \\
\hline Before(ppm) & 7.0 & 9.4 & 1.3 & 5.2 & 1.6 & 3.1 & 2.8 & 0.4 & 28.0 & 1.4 & 0.3 \\
After(ppm) $^{2}$ & 6.7 & 9.3 & 1.1 & 4.7 & 1.3 & 0.1 & 2.0 & 0.3 & 26.6 & 1.1 & 0.0 \\
\hline Element & $\mathrm{Dy}$ & $\mathrm{Ho}$ & $\mathrm{Er}$ & $\mathrm{Tm}$ & $\mathrm{Yb}$ & $\mathrm{Lu}$ & $\mathrm{Y}$ & $\mathrm{U}$ & $\mathrm{REEs}$ & $\% \mathrm{Fe}_{2} \mathrm{O}_{3}$ & $\% \mathrm{Al}_{2} \mathrm{O}_{3}$ \\
\hline Before(ppm) & 3.1 & 0.7 & 2.7 & 0.5 & 3.7 & 0.7 & 44.8 & 102.3 & 90.5 & 0.9 & 0.7 \\
After(ppm) & 2.2 & 0.3 & 1.9 & 0.4 & 3.4 & 0.6 & 52.8 & 102.7 & 87.1 & 1.0 & 0.7 \\
\hline
\end{tabular}

${ }^{1}$ WPA sample before pretreatment, ${ }^{2}$ WPA sample after pretreatment, \%Oxides: counted by weight percent.

Tab.2 Structural formula of extractants for REEs and U extraction from WPA

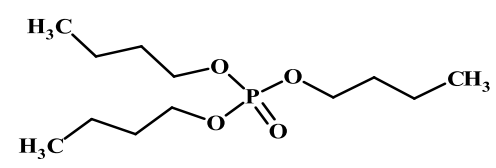

TBP

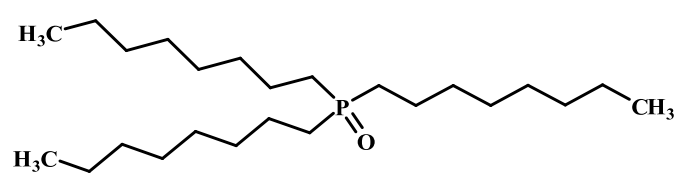

TOPO 


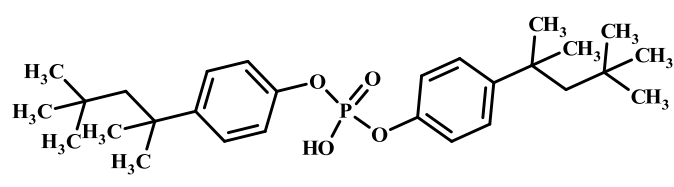

DOPPA

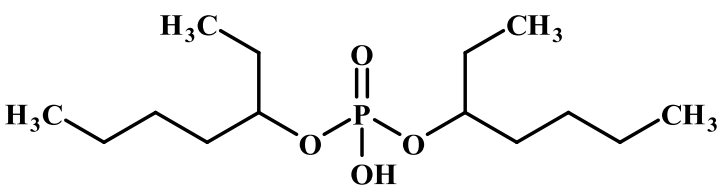

D2EHPA

\subsection{Apparatus and analysis}

Chemical composition of aqueous solution was analyzed by ICP-MS (Perkin Elmer Nexion 350X). Solution samples were diluted (100x or 250x) for major oxides analysis $\left(\mathrm{P}_{2} \mathrm{O}_{5}, \mathrm{MgO}, \mathrm{Fe}_{2} \mathrm{O}_{3}, \mathrm{Al}_{2} \mathrm{O}_{3}\right)$ and $50 \times$ for $\mathrm{Y}$ and $\mathrm{U}$. ICP standards for both REE and major oxides analyses were prepared from single elements standards purchased from Fischer Scientific (Doral, FL, USA). And the acidity of aqueous was measured by a pH meter

\subsection{Experimental runs}

Extraction and stripping experiments were conducted in conical flasks with intensive magnet stirring and the aqueous solution was separated from organic phase by the aid of separation funnel. D2EHPA, TBP, and TOPO were diluted in kerosene to prepare organic solution. Extraction of $\mathrm{U}(\mathrm{IV})$ and $\mathrm{U}(\mathrm{VI})$ were conducted before and after oxidation treatment of WPA with $50 \% \mathrm{H}_{2} \mathrm{O}_{2}$. The extraction performance was evaluated via the distribution coefficient $\left(D_{M}\right)$ and extraction efficiency $\left(E_{M}\right)$ of metal ions which were defined as following equations:

$$
\begin{aligned}
& \mathrm{D}_{\mathrm{M}}=\frac{\left([\mathrm{M}]_{\mathrm{ini}}-[\mathrm{M}]_{\mathrm{raf}}\right)\left(\frac{\mathrm{V}_{\mathrm{A}}}{\mathrm{V}_{\mathrm{O}}}\right)}{[\mathrm{M}]_{\mathrm{raf}}} \\
& \mathrm{E}_{\mathrm{M}}=\left(1-\frac{[\mathrm{M}]_{\mathrm{raf}}}{[\mathrm{M}]_{\mathrm{ini}}}\right) \times 100 \%
\end{aligned}
$$

Where $[\mathrm{M}]_{\mathrm{ini}}$ and $[\mathrm{M}]_{\mathrm{raf}}$ represent the concentrations of metal ions in the initial and raffinate aqueous solution, and $\mathrm{V}_{\mathrm{A}}$ and $\mathrm{V}_{\mathrm{O}}$ are the volumes of initial aqueous and organic solution.

Evaporation of phosphoric acid was conducted in a beaker with mild blade stirring in a water bath at $85-88^{\circ} \mathrm{C}$. Then concentrated phosphoric acid was separated from sludge by vacuum filtration with filter cloth.

\section{Results and discussion}

\subsection{Solvent extraction of REEs and U from WPA with D2EHPA, D2EHPA+TBP/TOPO}

It was commonly believed that REEs can be co-extracted in the industrial process of $\mathrm{U}$ recovery by D2EPHA+TBP and D2EHPA+TOPO. However, according to Solvay's experience, the widely adopted process for $\mathrm{U}$ extraction is insufficient to recover REEs (Rollat, 2016). But rare detailed data are available. Therefore, synergistic extraction of 
REEs and U from WPA with mixtures of D2EHPA+TBP and D2EHPA+TOPO were investigated.

As clearly demonstrated in Fig. 1 and Fig. 2, a growing synergistic effect for U extraction from WPA was achieved with increasing concentrations of TBP and TOPO in D2EHPA. Especially, a significant enhancement of $U$ extraction was obtained with the mixture of D2EHPA+TOPO. However, extraction efficiencies of HREEs decreased with increasing concentrations of TBP and TOPO, and the detrimental effect was more severe in the case of TOPO. In addition, extraction efficiencies of LREEs are all close to zero with these two kinds of mixture solvents. Furthermore, the loss of phosphorus in these extraction processes are $0.09 \%, 0.70 \%, 2.17 \% \mathrm{P}_{2} \mathrm{O}_{5}$ for $1.0 \mathrm{M}$ D2EHPA, $1.0 \mathrm{M}$ D2EHPA+0.1 M TBP, 1.0 M D2EHPA+0.1 M TOPO, respectively.

In conclusion, mixture solvents significantly decreased the extraction efficiencies of HREEs and increased the loss of phosphorus. But, known from Fig.1 and Fig. 2 that D2EHPA was possible to achieve simultaneous recovery of REEs and U. While data about simultaneous recovery of HREEs and U from industrial WPA with D2EHPA alone was rare reported, then studies on the effect of solvent concentration, mixing time, and organic-to-aqueous ratio on extraction efficiency of HREEs and $U$ are needed to obtain the optimal conditions.

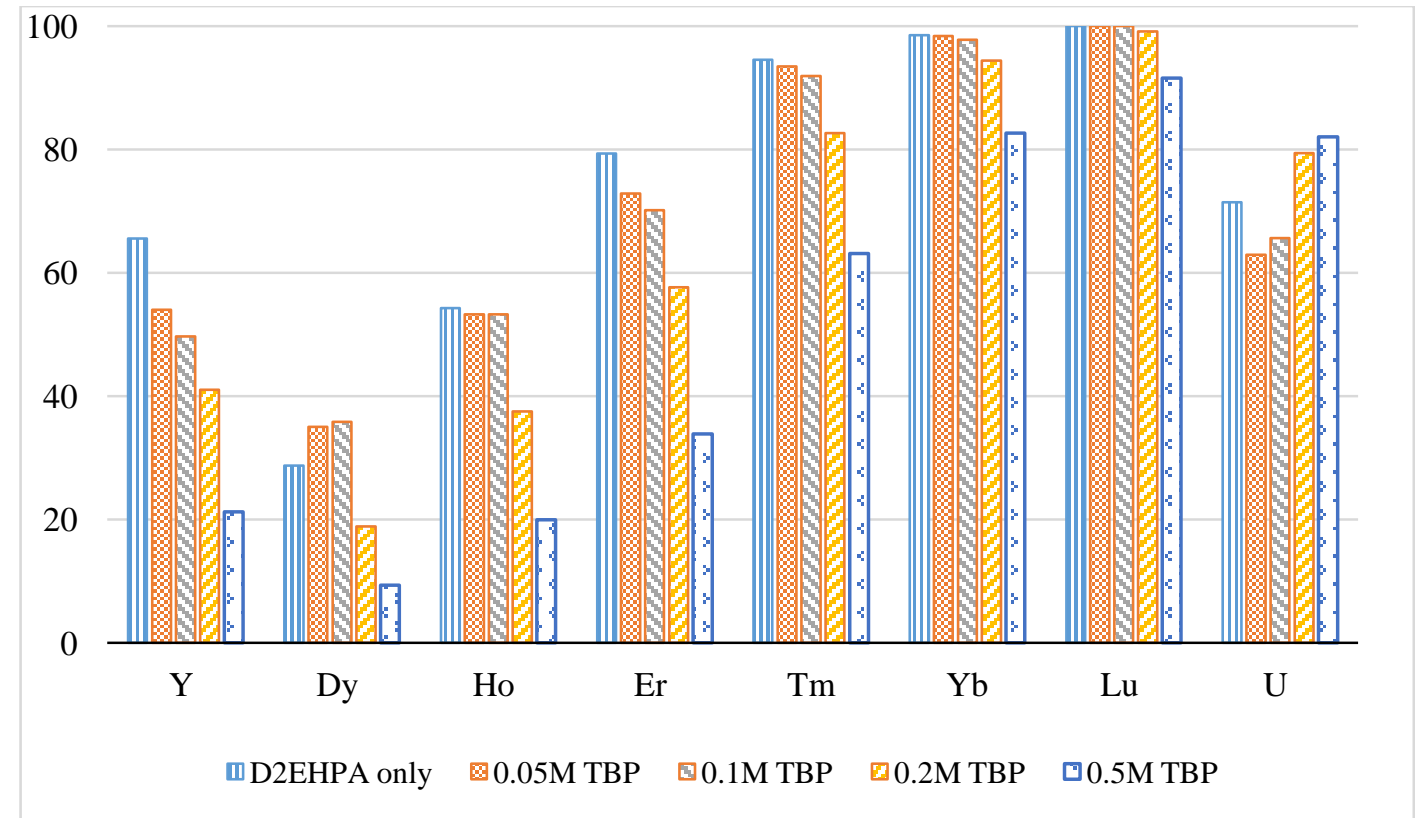

Fig. 1. Extraction efficiencies of REEs and U from WPA with mixture of 1.0M D2EHPA and TBP $\left(\mathrm{O} / \mathrm{A}=1: 1\right.$, mixing time: $15 \mathrm{~min}, 23{ }^{\circ} \mathrm{C}$, D2EHPA only: 1.0M D2EHPA without TBP addition) 


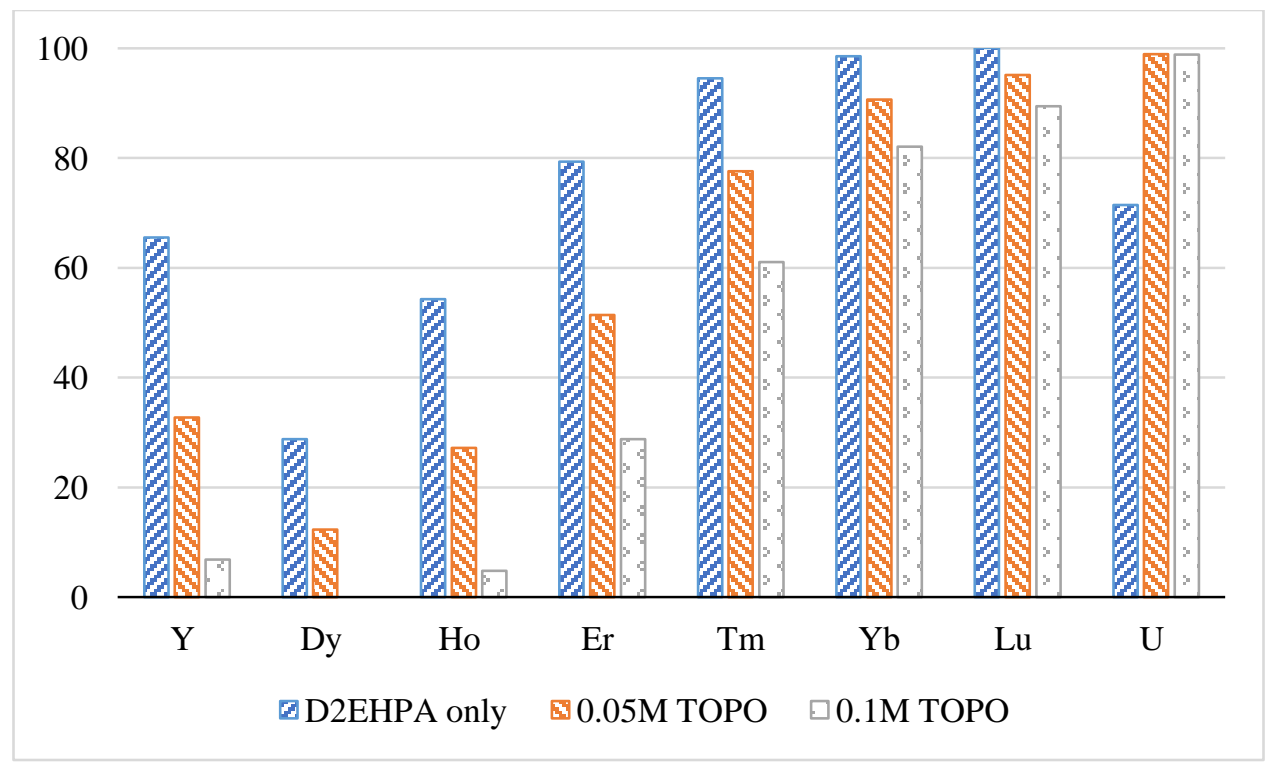

Fig. 2. Extraction efficiencies of REEs and U from WPA with mixture of 1.0 M D2EHPA and TOPO $\left(\mathrm{O} / \mathrm{A}=1: 1\right.$, mixing time: $15 \mathrm{~min}, 23{ }^{\circ} \mathrm{C}$, D2EHPA only: $1.0 \mathrm{M}$ D2EHPA without TOPO addition)

\subsection{Solvent extraction of HREEs and U from WPA with D2EHPA alone}

\subsubsection{Effect of mixing time on extraction of HREEs and U from WPA with D2EHPA}

The equilibrium time can be determined via the extraction kinetics curves. As shown in Fig. 3 and Fig. 4 ten minutes is sufficient for HREEs extraction from WPA. However, in order to guarantee the equilibrium of HREEs extraction was reached, the mixing time was set as fifteen minutes.

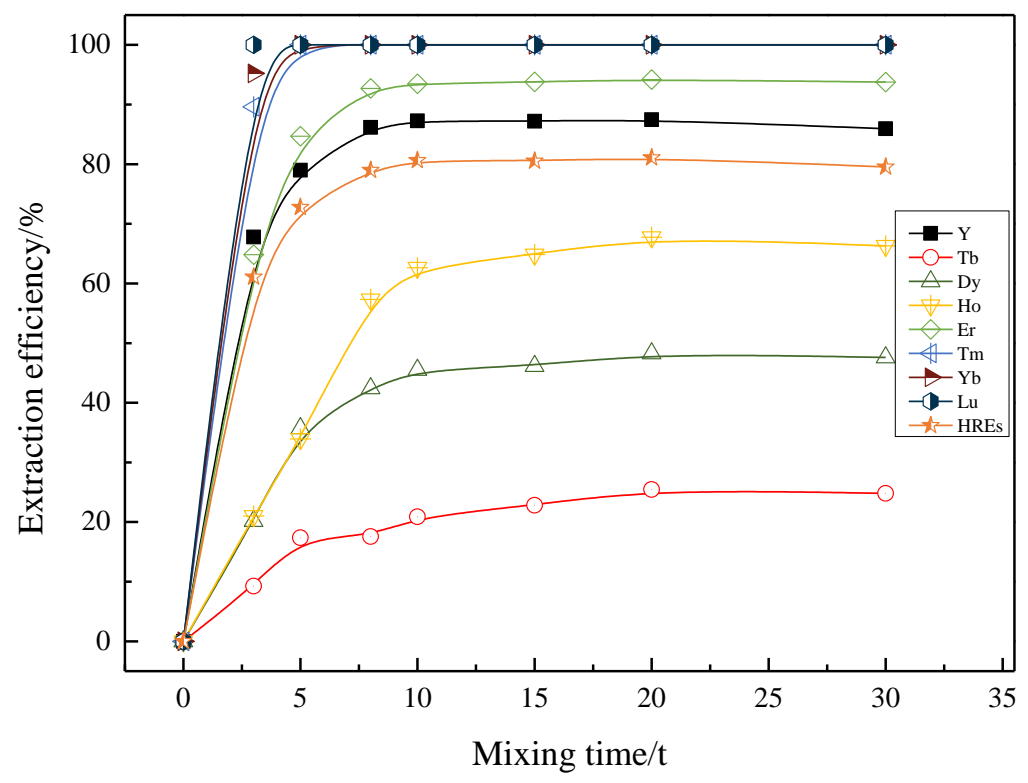

Fig. 3. Extraction kinetics of HREEs from WPA with 1.5 M D2EHPA $\left(\mathrm{O} / \mathrm{A}=1: 1,23{ }^{\circ} \mathrm{C}\right)$ 


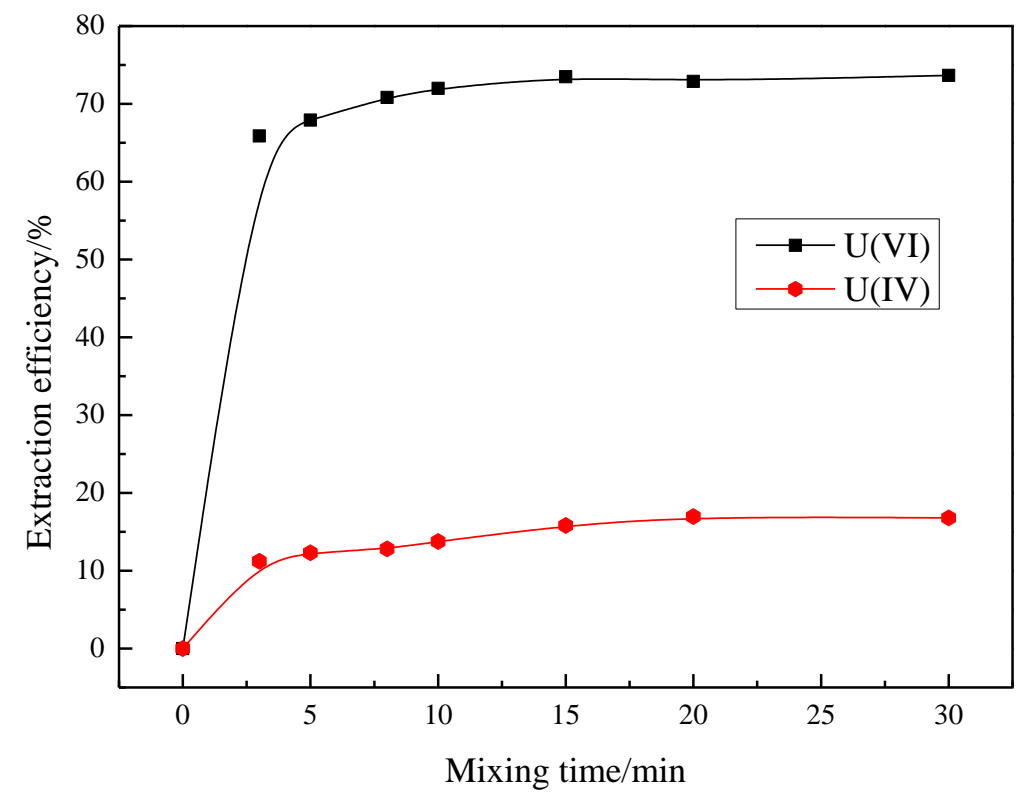

Fig. 4. Extraction kinetics of $\mathrm{U}(\mathrm{VI})$ and $\mathrm{U}(\mathrm{IV})$ from WPA with $1.5 \mathrm{M}$ D2EHPA $\left(\mathrm{O} / \mathrm{A}=1: 1,2{ }^{\circ} \mathrm{C}\right)$

\subsubsection{Effect of O/A ratio on the extraction efficiency of HREEs and $U$}

As is shown in Fig. 5 and Fig. 6, the extraction efficiencies of HREEs and $U$ increase with increasing value of O/A ratio. This could be attributed to the binding between HREEs and $U$ with extra D2EHPA that was brought into the extraction system via elevated organic to aqueous ratio. However, considering the large volume of WPA flow, O/A ratio should be reduced on the premise of effective extraction of HREEs and $U$. Therefore, $\mathrm{O} / \mathrm{A}=1: 1$ will be used in subsequent studies. 


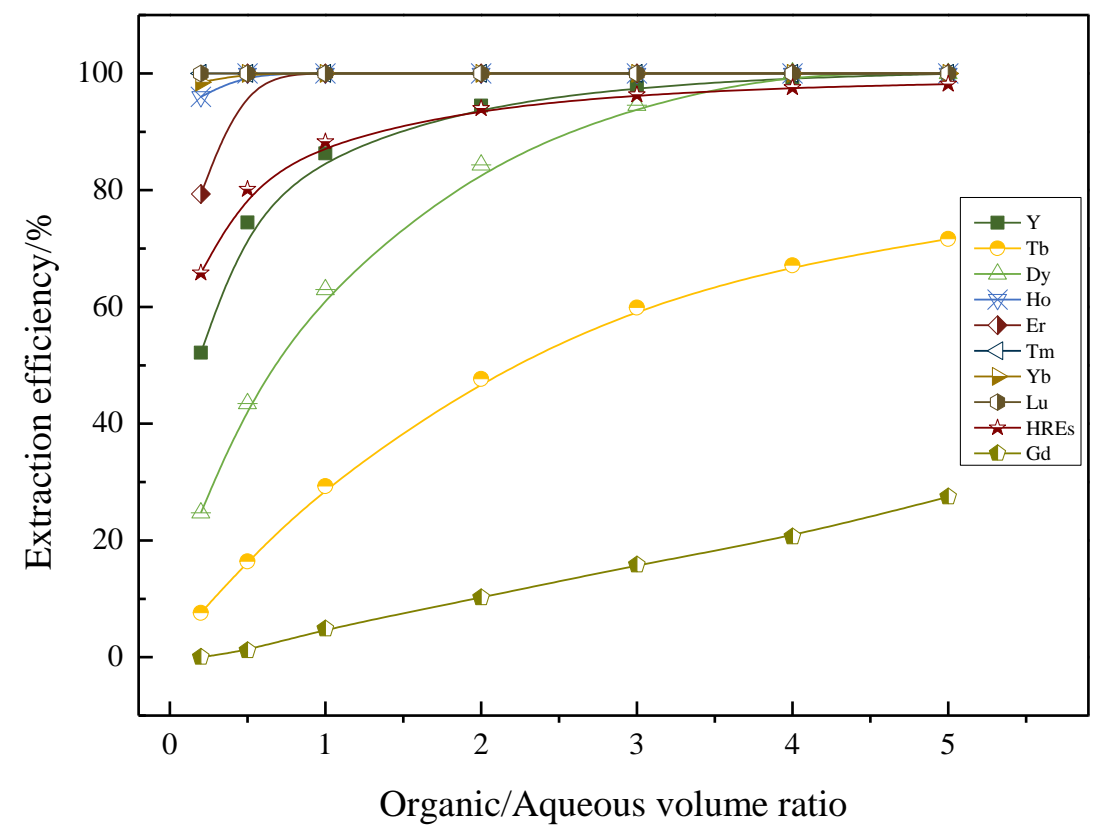

Fig. 5. Effect of organic/aqueous ratio on HREEs recovery from WPA solution (1.5 M D2EHPA, O/A=1:1, mixing time: $15 \mathrm{~min}, 23^{\circ} \mathrm{C}$ )

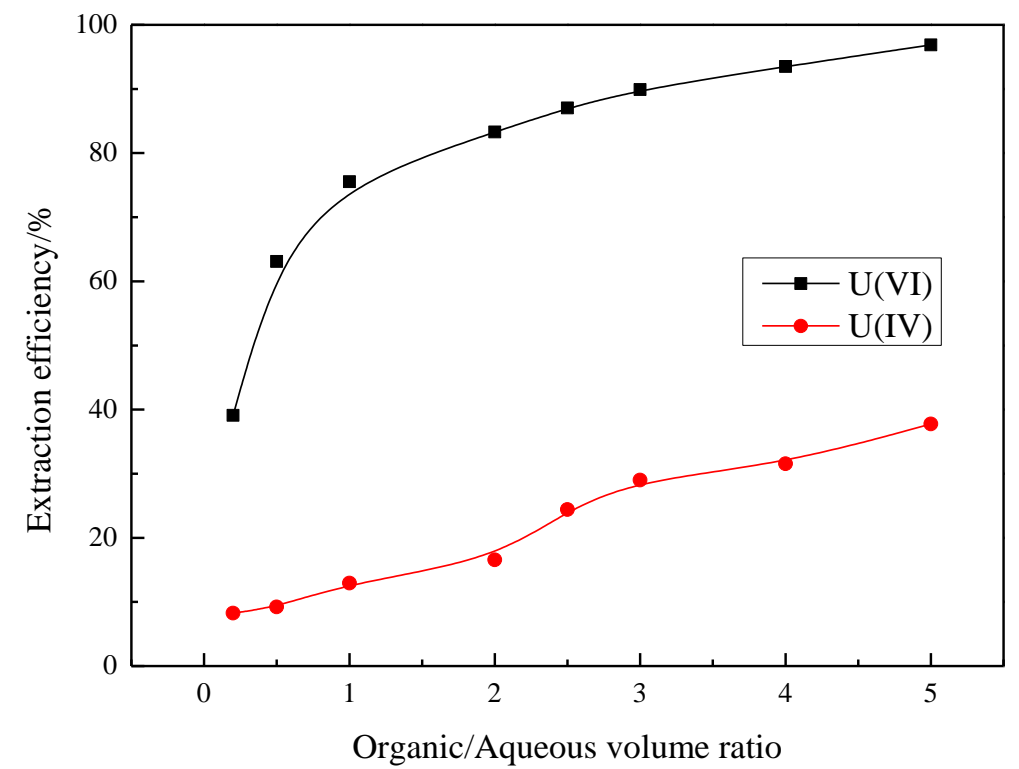

Fig. 6. Effect of organic/aqueous ratio on $U$ recovery from WPA solution (1.5 M D2EHPA, O/A=1:1, mixing time: $15 \mathrm{~min}, 23{ }^{\circ} \mathrm{C}$ ) 


\subsubsection{Effect of D2EHPA concentration on the extraction of HREEs and U from WPA}

The solvent extraction of REEs and U with D2EHPA from WPA is an ion exchange process between hydrogen ion and metal ions, which takes place at the interface between organic and aqueous phases (Geist et al., 1999). The extraction reaction can be described by equation below (Krea and Khalaf, 2000; Wang et al., 2011):

$$
\mathrm{M}^{\mathrm{n}+}+\mathrm{n} \overline{\mathrm{HL}} \leftrightarrow \overline{\mathrm{ML}_{\mathrm{m}}(\mathrm{HL})_{\mathrm{n}-\mathrm{m}}}+\mathrm{mH}^{+}
$$

Where $M$ represents metal ions such as REEs and $U, \overline{H L}$ represents D2EHPA, $\overline{\mathrm{ML}_{\mathrm{m}}(\mathrm{HL})_{\mathrm{n}-\mathrm{m}}}$ represents the coordination compounds. The equilibrium constant of equation (4) was written as $\mathrm{K}_{\mathrm{ex}}$ :

$$
\mathrm{K}_{\mathrm{ex}}=\frac{\left[\overline{\mathrm{M}(\mathrm{L} \cdot \mathrm{HL})_{\mathrm{n}}}\right]\left[\mathrm{H}^{+}\right]^{\mathrm{m}}}{\left[\mathrm{M}^{\mathrm{n}+}\right][\overline{\mathrm{HL}}]^{\mathrm{n}}}
$$

When $\mathrm{O} / \mathrm{A}=1: 1$, the extraction efficiency of metal ions $\left(\mathrm{E}_{\mathrm{M}}\right)$ can be defined as:

$$
\mathrm{E}_{\mathrm{M}}=\frac{\left[\overline{\mathrm{M}(\mathrm{L} \cdot \mathrm{HL})_{\mathrm{n}}}\right]}{\left[\mathrm{M}^{\mathrm{n}+}\right]+\left[\overline{\mathrm{M}(\mathrm{L} \cdot \mathrm{HL})_{\mathrm{n}}}\right]} \times 100 \%
$$

Combine equation (5) and equation (6) results in the following equation:

$$
\mathrm{E}_{\mathrm{M}}=\frac{1}{\mathrm{~K}_{\mathrm{ex}} \frac{\left[\mathrm{H}^{+}\right]^{\mathrm{m}}}{[\overline{\mathrm{HL}}]^{\mathrm{n}}}+1} \times 100 \%
$$

In equation (7), Kex is a constant under certain temperature. Hence, extraction efficiency of metal ion increases with increasing concentration of D2EHPA, which was shown as the extraction efficiency curves of HREEs and $U$ in Fig. 7 and Fig.8. However, an elevated concentration of D2EHPA in kerosene leads to the increasing viscosity of organic phase which retards the diffusion of proton and metal ions and results in difficulty of phase separation. Furthermore, stripping of metal ions become more difficult from a metal ion-loaded organic phase with concentrated D2EHPA in kerosene. In addition, it should be noted that extraction efficiencies of LREEs are all close to zero. 


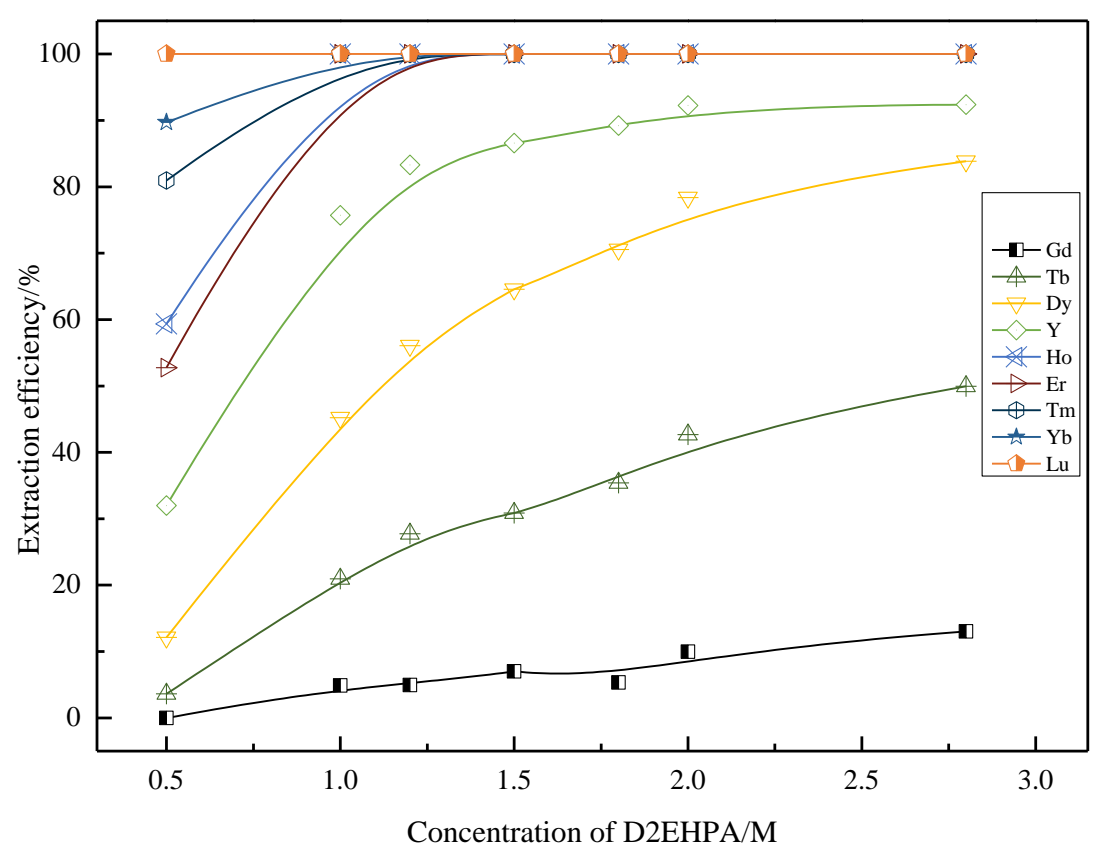

Fig. 7. Effect of D2EHPA concentration on HREEs recovery from WPA solution $\left(\mathrm{O} / \mathrm{A}=1: 1\right.$, mixing time: $\left.15 \mathrm{~min}, 23^{\circ} \mathrm{C}\right)$

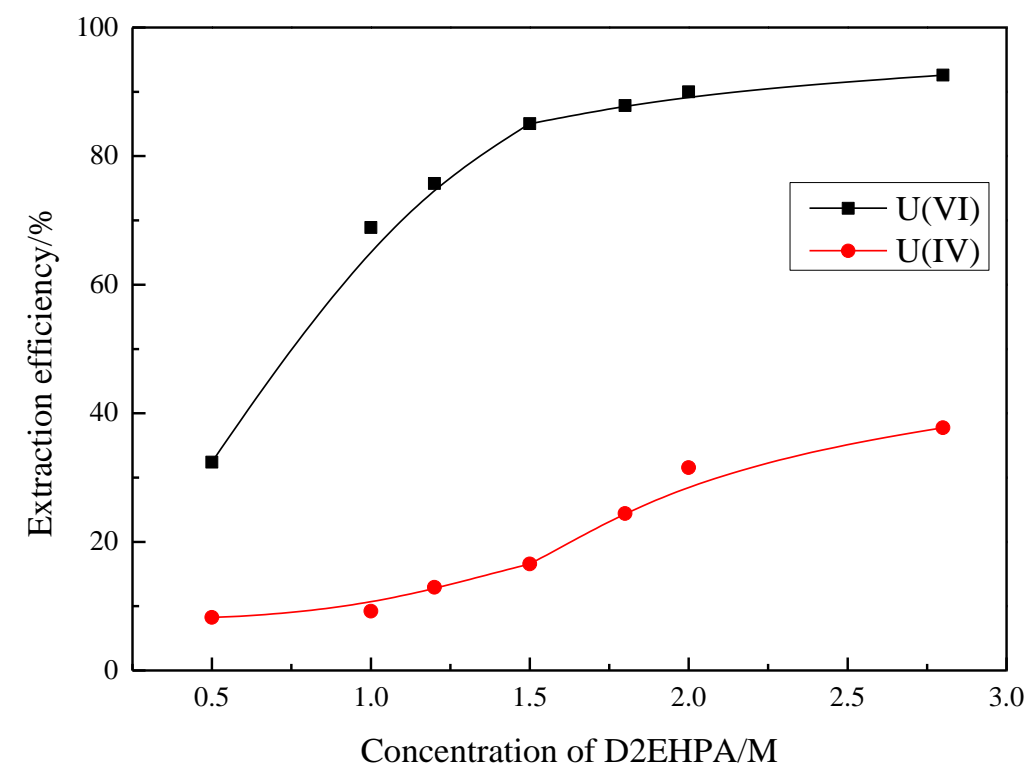

Fig. 8. Effect of D2EHPA concentration on extraction efficiency of U (VI) and U (IV) from WPA (U(VI) was obtained by oxidation treatment with $50 \% \mathrm{H}_{2} \mathrm{O}_{2} 0.01 \mathrm{~mL} / \mathrm{mL}$ WPA, $\mathrm{O} / \mathrm{A}=1: 1$, mixing time: $15 \min , 23{ }^{\circ} \mathrm{C}$ ) 
It was noted that $U$ presented in the form of U (IV) in WPA after pretreatment, and that D2EHPA is insufficient for U (IV) extraction since the extraction efficiency of U ranges from 10- 40\%. Fortunately, with $0.01 \mathrm{~mL}$ hydrogen peroxide $\left(\mathrm{H}_{2} \mathrm{O}_{2}\right) / \mathrm{mL}$ in WPA, significant enhancement on extraction efficiency of $U$ was achieved due to the oxidation of U (IV) to U (VI). In oxidized form, the binding between U and D2EHPA become more stable in term of the decreased steric hindrance caused by the smaller radius of $U$ (VI).

In conclusion, REEs and $U$ were simultaneously and effectively extracted from WPA by D2EHPA alone. And the optimal conditions for HREEs and U (VI) extraction from WPA with D2EHPA were determined as following: 1.0 M D2EHPA, O/A=1:1, mixing for $15 \mathrm{~min}$ at $23{ }^{\circ} \mathrm{C}$. Under the optimal conditions the two-stage accumulated extraction efficiencies of HREEs and U (VI) are $89.4 \%$ and $94.2 \%$, respectively.

\subsubsection{Mechanism of solvent extraction of REEs and U from WPA with D2EHPA}

According to equation (2), with a $\mathrm{O} / \mathrm{A}=1: 1$, the distribution coefficient is equal to the ratio of metal ionic concentrations in organic to aqueous phase:

$$
\mathrm{D}_{\mathrm{M}}=\frac{\left[\overline{\mathrm{M}(\mathrm{L} \cdot \mathrm{HL})_{\mathrm{n}}}\right]}{\left[\mathrm{M}^{\mathrm{n}+}\right]}=\mathrm{K}_{\mathrm{ex}} \frac{\left[\overline{(\mathrm{HL})_{2}}\right]^{\mathrm{n}}}{\left[\mathrm{H}^{+}\right]^{\mathrm{m}}}
$$

Conducting the equation (10) with logarithm transition, the equation can be expressed as:

$$
\log \mathrm{D}_{\mathrm{M}}=\log \mathrm{Kex}+\mathrm{nlog}[\overline{\mathrm{HL}}]-\operatorname{mlog}\left[\mathrm{H}^{+}\right]
$$

According to equation (11) the value of $\log \mathrm{D}_{\mathrm{M}} / \log [\overline{(\mathrm{HL})}]$ is equal to $\mathrm{n}$ that represents the stoichiometric number of D2EHPA. As shown in Fig. 9, the slopes of curves for Y, $\mathrm{Tb}$, and Dy representing heavy rare earth elements (HREEs) are all close to 2.0. That demonstrates that extraction of each HREE requires two D2EHPA molecules. Besides for the low level metal loading conditions, relatively high concentration of D2EHPA presents as dimer in the process of extraction.

On the other hand, in phosphoric acid solution, the dissociation process of $\mathrm{H}_{3} \mathrm{PO}_{4}$ can be expressed by the following equations:

$$
\begin{aligned}
\mathrm{H}_{3} \mathrm{PO}_{4} & \Leftrightarrow \mathrm{H}^{+}+\mathrm{H}_{2} \mathrm{PO}_{4}^{-} \\
\mathrm{H}_{2} \mathrm{PO}_{4}^{-} & \Leftrightarrow \mathrm{H}^{+}+\mathrm{HPO}_{4}^{2-} \\
\mathrm{HPO}_{4}^{2-} & \Leftrightarrow \mathrm{H}^{+}+\mathrm{PO}_{4}^{3-}
\end{aligned}
$$

The acid ionization constant $\mathrm{pK}$ for these three equations were defined as $\mathrm{pK}_{1}$ for equation (12), $\mathrm{pK}_{2}$ for equation (13), $\mathrm{pK}_{3}$ for equation (14), respectively. The value of the ionization constants are $\mathrm{pK}_{1}=2.14, \mathrm{pK}_{2}=7.20, \mathrm{pK}_{3}=12.34$ (Powell et al., 2005) and the $\mathrm{pH}$ value of WPA is about 0.65 . Which demonstrated that phosphorus was mainly presented in form of $\mathrm{H}_{3} \mathrm{PO}_{4}{ }^{0}$ and $\mathrm{H}_{2} \mathrm{PO}_{4}{ }^{-}$in 4-6 $\mathrm{M} \mathrm{H}_{3} \mathrm{PO}_{4}$ (for dihydrate process). Hence the reaction equation of HREEs extraction from WPA with D2EHPA can be written as: 


$$
\operatorname{HREE}\left(\mathrm{H}_{2} \mathrm{PO}_{4}\right)^{2+}+2 \overline{(\mathrm{HL})_{2}} \leftrightarrow \overline{\operatorname{HREE}\left(\mathrm{H}_{2} \mathrm{PO}_{4}\right)(\mathrm{L} \cdot \mathrm{HL})_{2}}+2 \mathrm{H}^{+}
$$

As demonstrated in Fig.10, the slope for U (IV) extraction curve is close to 1.0, based on the possible complexes with $\left(\mathrm{H}_{2} \mathrm{PO}_{4}\right)^{-}$, the extraction equation was deduced as:

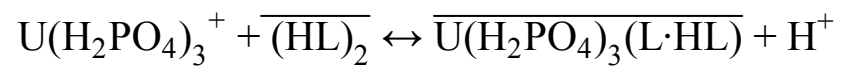

According to the studies by Bunus et al. (Bunus and Dumitrescu, 1986) and Beltrami et al. (Beltrami et al., 2014), U (VI) generally formed $\mathrm{UO}_{2}(\mathrm{~L} \cdot \mathrm{HL})_{2}$ with D2EHPA, and the slope of $\log \mathrm{D}_{\mathrm{M}} / \log [\overline{(\mathrm{HL})}]$ of $\mathrm{U}(\mathrm{VI})$ was close to 2.0 (Fig. 11). Therefore, extraction mechanism of $\mathrm{U}(\mathrm{VI})$ with D2EHPA was cation exchange, and complex ion of $\mathrm{U}$ (VI) was of +2 valence, the most possible form was $\mathrm{UO}_{2}\left(\mathrm{H}_{3} \mathrm{PO}_{4}\right)_{2}{ }^{2+}$. Thus, the solvent extraction equation of $\mathrm{U}(\mathrm{VI})$ from WPA with D2EHPA can be written as:

$$
\mathrm{UO}_{2}\left(\mathrm{H}_{3} \mathrm{PO}_{4}\right)_{2}{ }^{2+}+2 \overline{(\mathrm{HL})_{2}} \leftrightarrow \overline{\mathrm{UO}_{2}\left(\mathrm{H}_{3} \mathrm{PO}_{4}\right)_{2}(\mathrm{~L} \cdot \mathrm{HL})_{2}}+2 \mathrm{H}^{+}
$$

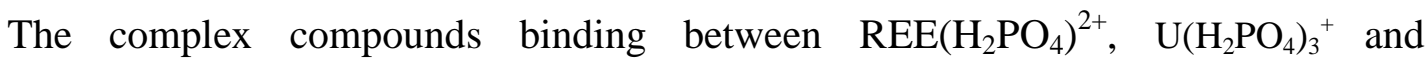
$\mathrm{UO}_{2}\left(\mathrm{H}_{3} \mathrm{PO}_{4}\right)_{2}{ }^{2+}$ with D2EHPA can be drawn as the following structure (Tab. 3):

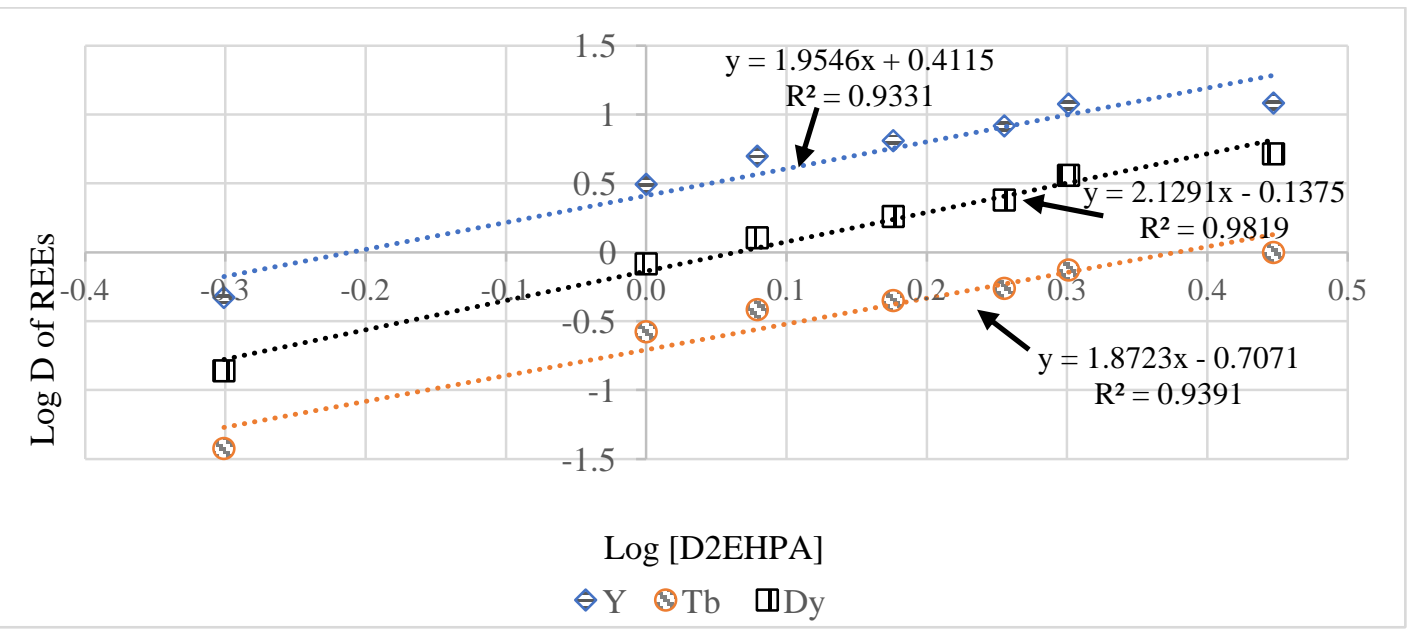

Fig.9 Log D of HREEs vs. $\log [\mathrm{D} 2 \mathrm{EHPA}]$ at a phase ratio of 1/1

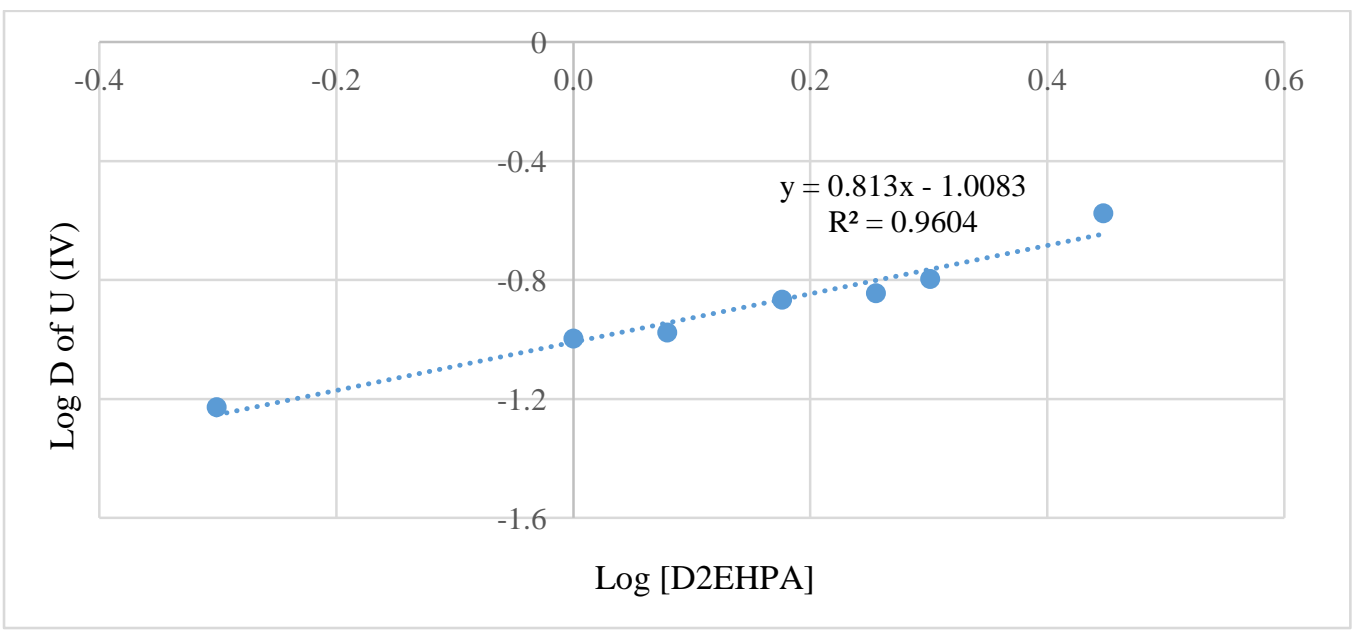

Fig.10 Log D of U (IV) vs. $\log [\mathrm{D} 2 \mathrm{EHPA}]$ at a phase ratio of $1 / 1$ 


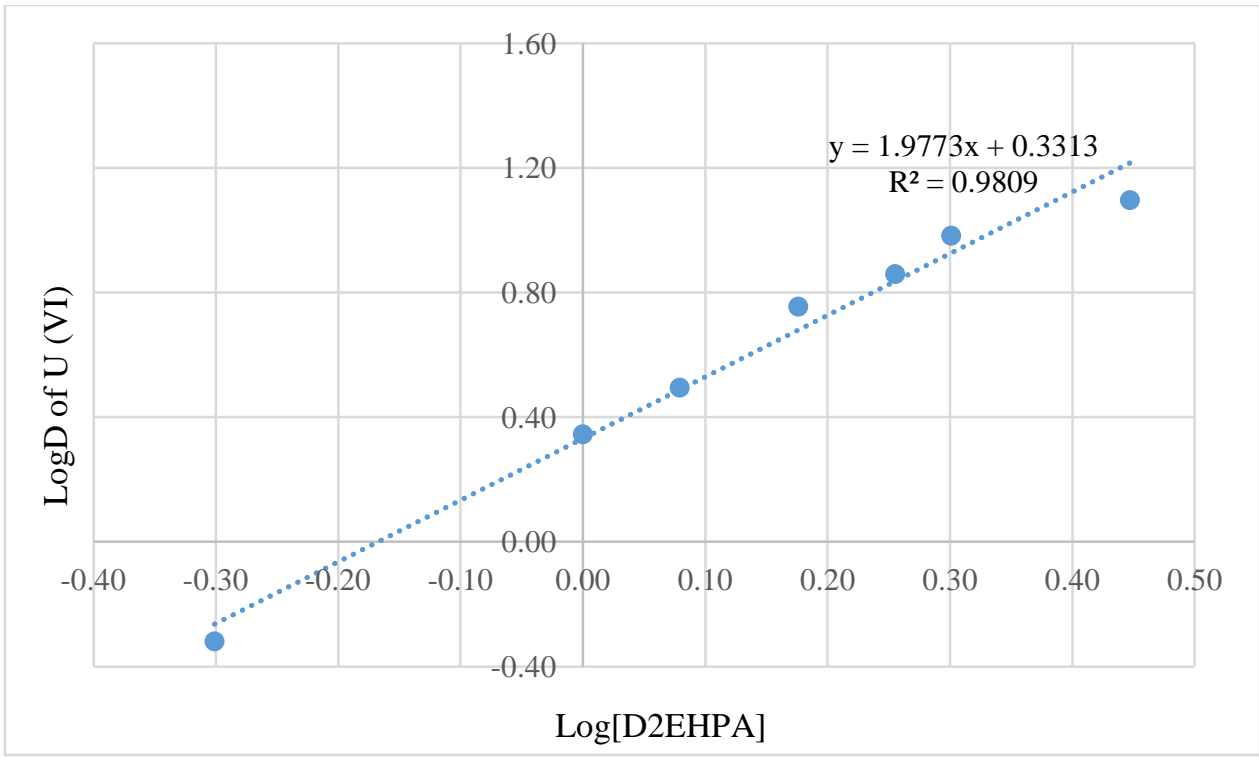

Fig.11 Log D of U (VI) vs. $\log [\mathrm{D} 2 \mathrm{EHPA}]$ at a phase ratio of $1 / 1$

Tab.3 Molecule structures of complexes between metal ions and D2EHPA
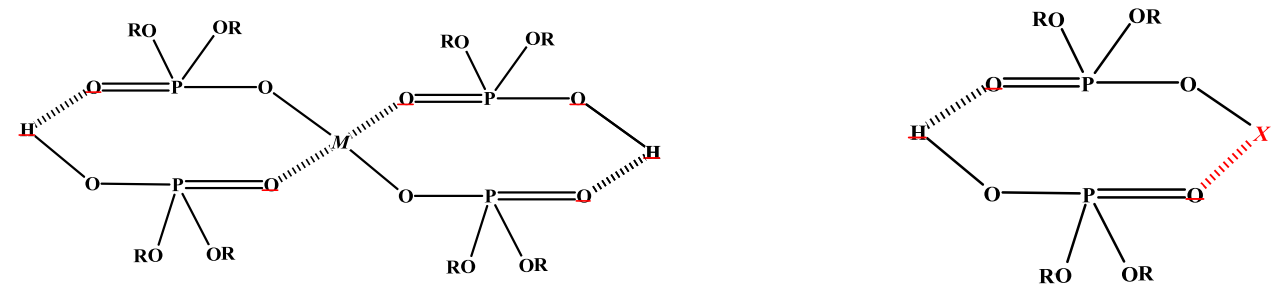

Complex of $\mathrm{HREE}\left(\mathrm{H}_{2} \mathrm{PO}_{4}\right)^{2+}$ and $\mathrm{UO}_{2}\left(\mathrm{H}_{3} \mathrm{PO}_{4}\right)^{2+}$ (represents as $\mathrm{M}$ ) binding with D2EHPA
Complex of $\mathrm{U}\left(\mathrm{H}_{2} \mathrm{PO}_{4}\right)_{3}{ }^{+}$(represents as $\mathrm{X})$ binding with D2EHPA

\subsubsection{Selective stripping of HREEs from loaded organic phase}

High concentration $\mathrm{HCl}(6 \mathrm{M})$ was used for selective stripping of HREEs from loaded D2EHPA owing to its wide industrial application. Stripping experiments demonstrated that $98.1 \%$ of accumulated stripping efficiency was achieved via three stages, and the loss of $\mathrm{U}$ during the process was less than $1 \%$. Moreover, it was found that the HREEs can be accumulated in $\mathrm{HCl}$ solution via circulating the aqueous solution (Fig. 12). The maximum concentration of HREEs in $\mathrm{HCl}$ solution was determined by the distribution coefficiencies of HREEs between organic and aqueous phases as well as the initial concentration of HREEs in loaded organic phase. For uranium, $97.8 \%$ of stripping rate was achieved with $15 \% \mathrm{HF}$ or $20 \% \mathrm{Na}_{2} \mathrm{CO}_{3}$. 


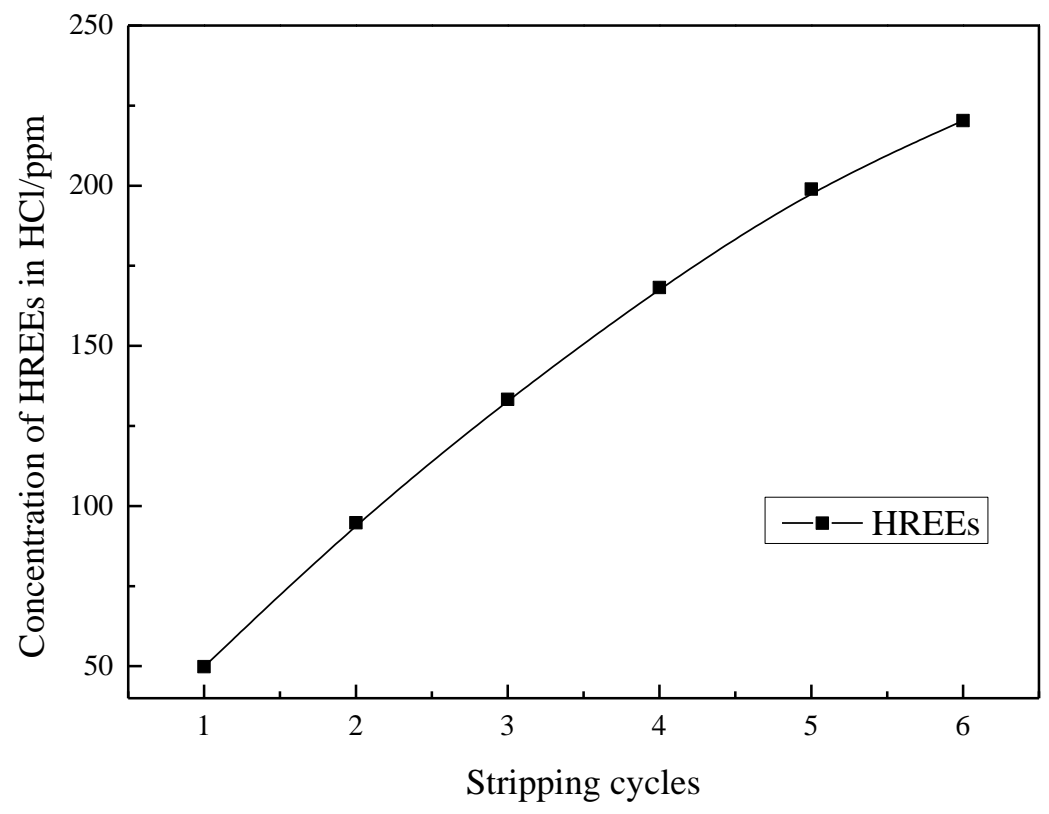

Fig. 12. Selective stripping of HREEs from loaded D2EHPA with $6 \mathrm{M} \mathrm{HCl}$ (6 recycles)

$\left(\mathrm{O} / \mathrm{A}=1: 1,2{ }^{\circ} \mathrm{C}\right.$, HREEs in loaded D2EHPA is $\left.58.8 \mathrm{ppm}\right)$

\subsection{Precipitation of LREEs from WPA via evaporation}

Known from previous studies, D2EHPA is insufficient for LREEs extraction from WPA (Bunus et al., 1994). Our results also shown that LREEs were completely left in raffinate after two stages of solvent extraction of HREEs and U with D2EHPA. Fortunately, solubility of REEs in phosphoric acid shows a dramatic difference from that of $\mathrm{REEPO}_{4}$ in non-phosphate solution. LREEs have far lower solubility in WPA than HREEs, for example, solubility of $\mathrm{Y}_{2} \mathrm{O}_{3}$ in WPA is about $48.8 \mathrm{~g} / \mathrm{L}$ while solubility of $\mathrm{La}_{2} \mathrm{O}_{3}$ is about $0.18 \mathrm{~g} / \mathrm{L}$ (Lokshin et al., 2007). Therefore, evaporation method-a general process for the commercial grade phosphoric acid production was adopted for LREEs enrichment from WPA. The chemical analysis of evaporation sludge is given in Tab.4, and the composition of concentrated phosphoric acid is displayed in Tab.5. The results demonstrate that more than $90 \%$ of TLREEs were precipitated and enriched in evaporation sludge with a concentration of 1204.3 ug/g LREEs. Furthermore, 77.4\% precipitation ratio was also achieved for $\mathrm{Gd}$ which has a relatively low extraction efficiency with D2EHPA from WPA.

Tab.4 Composition of evaporation sludge (ICP-MS)

\begin{tabular}{cccccccccccc}
\hline Element & $\mathrm{La}$ & $\mathrm{Ce}$ & $\mathrm{Pr}$ & $\mathrm{Nd}$ & $\mathrm{Sm}$ & $\mathrm{Eu}$ & $\mathrm{Gd}$ & $\mathrm{Tb}$ & $\% \mathrm{P}_{2} \mathrm{O}_{5}$ & $\% \mathrm{MgO}$ & $\% \mathrm{Na}$ \\
\hline Con./ppm & 351.9 & 481.6 & 56.4 & 257.9 & 48.2 & 8.3 & 47.6 & 3.4 & 30.1 & 0.8 & 0.6 \\
\hline Element & $\mathrm{Dy}$ & $\mathrm{Ho}$ & $\mathrm{Er}$ & $\mathrm{Tm}$ & $\mathrm{Yb}$ & $\mathrm{Lu}$ & $\mathrm{Y}$ & $\mathrm{U}$ & $\% \mathrm{Al}_{2} \mathrm{O}_{3}$ & $\% \mathrm{Fe}_{2} \mathrm{O}_{3}$ & $\% \mathrm{~K}$ \\
\hline
\end{tabular}




\begin{tabular}{llllllllllllll}
\hline Con./ppm & 6.4 & 0.0 & 0.0 & 0.0 & 0.0 & 0.0 & 0.0 & 0.0 & 1.6 & 0.7 & 0.1 \\
\hline
\end{tabular}

Tab.5 Concentration of ions in concentrated phosphoric acid $\left(54 \% \mathrm{P}_{2} \mathrm{O}_{5}\right)$

\begin{tabular}{cccccccccccc}
\hline Element & $\mathrm{La}$ & $\mathrm{Ce}$ & $\mathrm{Pr}$ & $\mathrm{Nd}$ & $\mathrm{Sm}$ & $\mathrm{Eu}$ & $\mathrm{Gd}$ & $\mathrm{Tb}$ & $\% \mathrm{P}_{2} \mathrm{O}_{5}$ & $\% \mathrm{MgO}$ & $\% \mathrm{Na}$ \\
\hline Lab(ppm) & 0.4 & 0.6 & 0.1 & 0.5 & 0.5 & 0.2 & 1.9 & 0.3 & 55.9 & 1.4 & 0.0 \\
Plant(ppm) & 0.6 & 0.6 & 0.1 & 0.3 & 0.2 & 0.1 & 0.9 & 0.3 & 56.0 & 1.1 & $\mathrm{ND}$ \\
\hline Element & $\mathrm{Dy}$ & $\mathrm{Ho}$ & $\mathrm{Er}$ & $\mathrm{Tm}$ & $\mathrm{Yb}$ & $\mathrm{Lu}$ & $\mathrm{Y}$ & $\mathrm{U}$ & $\% \mathrm{Al}_{2} \mathrm{O}_{3}$ & $\% \mathrm{Fe}_{2} \mathrm{O}_{3}$ & $\% \mathrm{~K}$ \\
\hline Lab$(\mathrm{ppm})$ & 1.3 & 0.1 & 0.1 & 0.0 & 0.0 & 0.0 & 2.6 & 2.0 & 2.3 & 1.5 & 0.0 \\
Plant(ppm) & 2.9 & 0.9 & 4.5 & 0.9 & 7.1 & 1.5 & 75.9 & 235.0 & 1.0 & 1.7 & $\mathrm{ND}$ \\
\hline
\end{tabular}

a: concentrated phosphoric acid obtained by lab-scale experiment. b: concentrated phosphoric acid produced by plant. \%Oxides: counted by weight percent. ND: not determined.

Moreover, a significant improvement on filtration speed of concentrated phosphoric acid $\left(54 \% \mathrm{P}_{2} \mathrm{O}_{5}\right)$ was achieved in the case of evaporation process of green acid. In practice, in order to extract HREEs and U from WPA at the same time, the WPA solution was required to go through an uranium (U (IV)) oxidation treatment to obtain the brown acid. While the brown acid is difficult to filter afterward. It is also a major issue in commercial grade phosphoric acid production. Oxidation process of WPA with $50 \% \mathrm{H}_{2} \mathrm{O}_{2}$ was investigated to achieve a good filtration performance concentrated phosphoric acid. It was noted that the oxidized brown WPA solution turned green gradually during the long time standing (Table. 6). Which demonstrates that the $\mathrm{Fe}^{2+}$ ions were oxidized to $\mathrm{Fe}^{3+}$ at beginning and then reduced back to $\mathrm{Fe}^{2+}$. This mechanism was illustrated by Singh et al. (Singh et al., 2001) that redox potential of WPA was elevated by addition of $50 \% \mathrm{H}_{2} \mathrm{O}_{2}$ until reaching the maximum value in a short period of time and then decreased gradually and the maximum redox potential was determined by the dosage of $\mathrm{H}_{2} \mathrm{O}_{2}$. Therefore, treated WPA with $50 \% \mathrm{H}_{2} \mathrm{O}_{2}$ for the extraction of U(VI) and HREEs, and then stood the raffinate for more than $12 \mathrm{~h}$ before the evaporation operation to achieve LREEs enrichment and an easy-to-filter concentrated phosphoric acid.

Table.6 Color change of WPA before and after oxidation

\begin{tabular}{l|l|l|l|l}
\hline Before oxidation & 60 s after oxidation & 3h after oxidation & $\begin{array}{c}7 \mathrm{~h} \text { after } \\
\text { oxidation }\end{array}$ & $\begin{array}{c}20 \mathrm{~h} \text { after } \\
\text { oxidation }\end{array}$ \\
\hline & & & \\
\hline
\end{tabular}

Note: the right one is the fresh WPA suffered pretreatment, the left one has gone through one oxidation operation. 
3.4 Suggested alternative process for recovery of REEs and $U$.

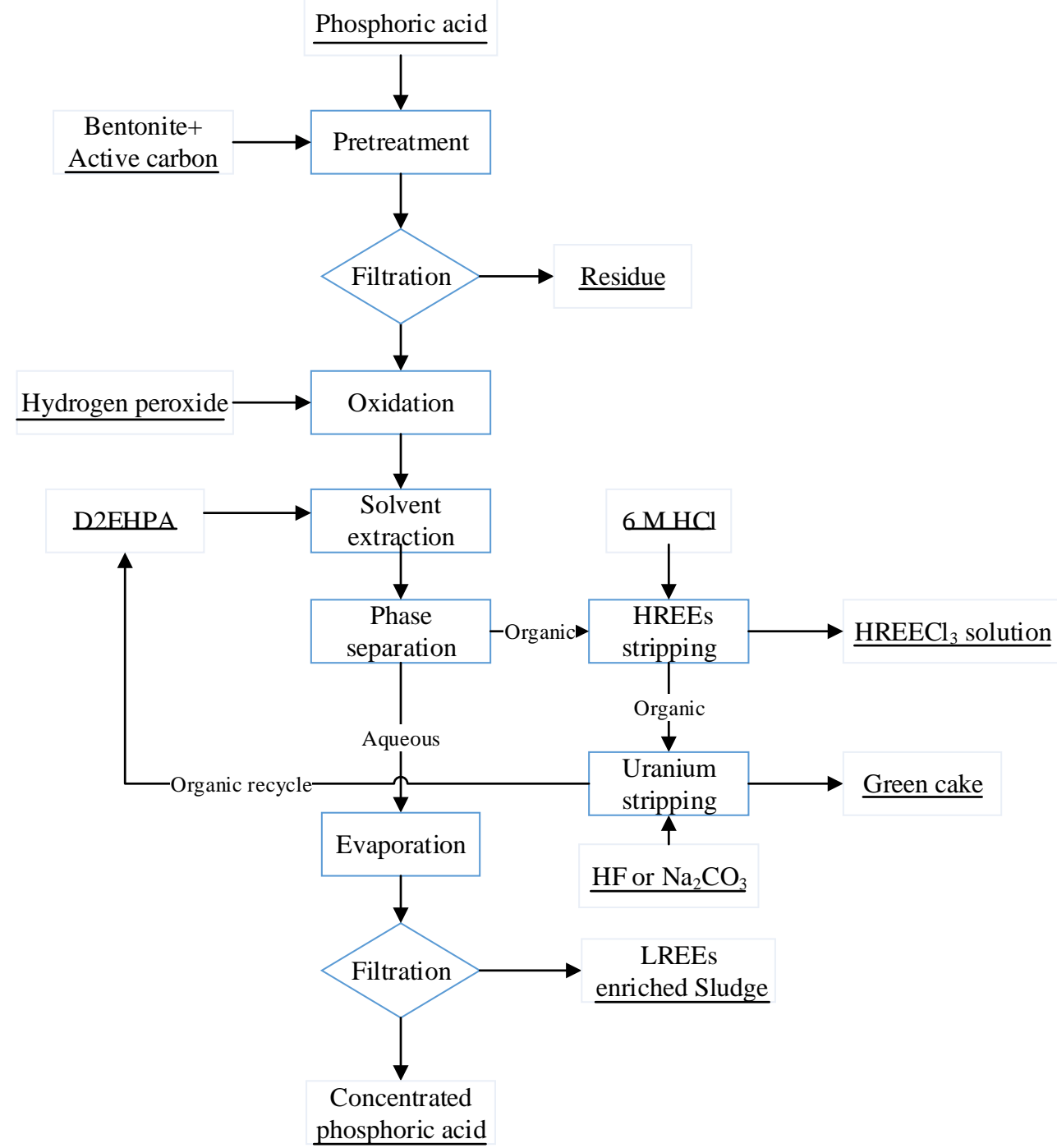

Fig. 13 An alternative process for simultaneous recovery and grouping of HREEs, LREEs and U from WPA

Based on the studies above, an alternative process was proposed and recommended for recovery and grouping of HREEs, LREEs and U from WPA (Fig. 13). In this process, WPA was treated with activated carbon and bentonite before filtration, then HREEs and U were extracted from WPA with $1.0 \mathrm{M}$ D2EHPA. $6.0 \mathrm{M} \mathrm{HCl}$ solution was used to selectively stripped HREEs from loaded D2EHPA, followed by U stripping by 5- 15\% HF or $10-20 \% \mathrm{Na}_{2} \mathrm{CO}_{3}$ solutions. LREEs that were left in raffinate would be enriched by heating WPA up to $85-88{ }^{\circ} \mathrm{C}$ and insulated for several hours until the phosphoric acid was concentrated to $54 \% \mathrm{P}_{2} \mathrm{O}_{5}$. In this process, more than $90 \%$ of REEs and $\mathrm{U}$ were removed and recovered from phosphoric acid. 


\section{Conclusions}

Simultaneous extraction of HREEs and U was achieved by 1.0 M D2EHPA alone, the accumulated two-stage extraction efficiencies for HREEs and $U$ are $89.4 \%$ and $94.2 \%$ under the optimal conditions: $\mathrm{O} / \mathrm{A}=1: 1$, mixing $15 \mathrm{~min}$, at $23^{\circ} \mathrm{C} .98 .1 \%$ HREEs were selectively stripped by $6.0 \mathrm{M} \mathrm{HCl}$ via three stages and $97.8 \% \mathrm{U}$ was then precipitated by $15 \% \mathrm{HF}$ or $20 \% \mathrm{Na}_{2} \mathrm{CO}_{3}$. LREEs were enriched during the evaporation process in a easy-soluble form and the filtration performance of concentrated phosphoric acid was significantly improved. Based on the studies above, a alternative process is developed to recover REEs and $U$ from WPA, that avoids the complex process of REEs separation from green cake. And the preliminary experimental results showed that more than $90 \%$ of REEs and U were recovered.

\section{Acknowledgements}

The authors gratefully acknowledge the financial support from the following projects: the program of the National Natural Science Foundation of China (NSFC: 51674036); the US Department of Energy under the Critical Materials Institute (CMI project 1.1.2); Beijing Nova program (Z161100004916108); and China Scholarship Council.

\section{References}

Abreu, R.D. and Morais, C.A., 2010. Purification of rare earth elements from monazite sulphuric acid leach liquor and the production of high-purity ceric oxide. Miner. Eng., 23(6): 536540.

Al-Thyabat, S. and Zhang, P., 2015a. In-line extraction of REE from Dihydrate (DH) and HemiDihydrate (HDH) wet processes. Hydrometallurgy, 153: 30-37.

Al-Thyabat, S. and Zhang, P., 2015b. REE extraction from phosphoric acid, phosphoric acid sludge, and phosphogypsum. Mineral Processing and Extractive Metallurgy (Trans. Inst. Min Metall. C), 124(3): 143-150.

Apergis, E. and Apergis, N., 2017. The role of rare earth prices in renewable energy consumption: The actual driver for a renewable energy world. Energy Economics, 62: 33-42.

Beltrami, D. et al., 2014. Recovery of uranium from wet phosphoric acid by solvent extraction processes. Chem. Rev., 114(24): 12002-12023.

Bunus, F. and Dumitrescu, P., 1986. Uranium(VI) extraction from acid mixtures with organophosphorus esters. Hydrometallurgy, 16(2): 167-175.

Bunus, F. and Dumitrescu, R., 1992. Simultaneous extraction of rare earth elements and uranium from phosphoric acid. Hydrometallurgy, 28(3): 331-338.

Bunus, F., Miu, I. and Dumitrescu, R., 1994. Simultaneous recovery and separation of uranium and rare earths from phosphoric acid in a one-cycle extraction-stripping process. Hydrometallurgy, 35(3): 375-389.

Bunus, F.T., 2000. Uranium and rare earth recovery from phosphate fertilizer industry by solvent extraction. Mineral Processing and Extractive Metullargy Review, 21(1-5): 381-478.

Geist, A., Nitsch, W. and Kim, J.-I., 1999. On the kinetics of rare-earth extraction into D2EHPA. Chem. Eng. Sci., 54(12): 1903-1907.

Habashi, F., 1985. The recovery of the lanthanides from phosphate rock. Journal of Chemical Technology and Biotechnology. Chemical Technology, 35(1): 5-14.

Habashi, F., 2013. Extractive metallurgy of rare earths. Can. Metall. Q., 52(3): 224-233. 
Hurst, F.J. and Crouse, D., 1974. Recovery of uranium from wet-process phosphoric acid by extraction with octylphenylphosphoric acid. Industrial \& Engineering Chemistry Process Design and Development, 13(3): 286-291.

Krea, M. and Khalaf, H., 2000. Liquid-liquid extraction of uranium and lanthanides from phosphoric acid using a synergistic DOPPA-TOPO mixture. Hydrometallurgy, 58(3): 215-225.

Krishnamurthy, N. and Gupta, C.K., 2004. Extractive metallurgy of rare earths. CRC press.

Liu, Z. and Li, H., 2015. Metallurgical process for valuable elements recovery from red mud-A review. Hydrometallurgy, 155: 29-43.

Lokshin, E., Tareeva, O., Ivlev, K. and Kashulina, T., 2005. Solubility of double alkali metal (Na, $\mathrm{K})$ rare-earth $(\mathrm{La}, \mathrm{Ce})$ sulfates in sulfuric-phosphoric acid solutions at $20 \mathrm{C}$. Russ. J. Appl. Chem., 78(7): 1058-1063.

Lokshin, E., Vershkova, Y.A., Ivlev, K. and Tareeva, O., 2004. $\mathrm{LaF}_{3}$ and $\mathrm{YbF}_{3}$ solubilities in solutions containing sulfuric and phosphoric acids. Russian journal of inorganic chemistry, 49(4): 645-648.

Lokshin, E.P., Tareeva, O. and Kashulina, T., 2007. A study of the solubility of yttrium, praseodymium, neodymium, and gadolinium sulfates in the presence of sodium and potassium in sulfuric-phosphoric acid solutions at $20^{\circ}$ C. Russ. J. Appl. Chem., 80(8): 1275-1280.

Lokshin, E.P., Tareeva, O.A. and Elizarova, I.R., 2011. Deposition of rare earth elements from a wet-process phosphoric acid by fluorine compounds. Russ. J. Appl. Chem., 84(5): 773781.

Powell, K.J. et al., 2005. Chemical speciation of environmentally significant heavy metals with inorganic ligands. Part 1: The $\mathrm{Hg} 2+-\mathrm{Cl}-, \mathrm{OH}-, \mathrm{CO} 32-$, SO42-, and $\mathrm{PO} 43-$ aqueous systems (IUPAC Technical Report). Pure Appl. Chem., 77(4): 739-800.

Ragheb, M., 2010. Uranium resources in phosphate rocks. Nuclear, Plasma and Radiation Science, Inventing the Future.

Reddy, B.R., Kumar, B.N. and Radhika, S., 2009. Solid - Liquid Extraction of Terbium from Phosphoric Acid Medium using Bifunctional Phosphinic Acid Resin, Tulsion CH - 96. Solvent Extr. Ion Exch., 27(5-6): 695-711.

Reddy, B.R., Radhika, S. and Kumar, B.N., 2010. Liquid-liquid extraction studies of trivalent yttrium from phosphoric acid solutions using TOPS 99 as an extractant. Sep. Sci. Technol., 45(10): 1426-1432.

Rollat, A., 2016. Recovery of Rare Earths from Wet-Process Phosphoric Acid, the Solvay Experience. Procedia Engineering, 138: 273-280.

Singh, H., Vijayalakshmi, R., Mishra, S.L. and Gupta, C.K., 2001. Studies on uranium extraction from phosphoric acid using di-nonyl phenyl phosphoric acid-based synergistic mixtures. Hydrometallurgy, 59(1): 69-76.

Sivaprakash, G., 1989. Uranium recovery from phosphoric acid.

Wang, L. et al., 2010. Recovery of rare earths from wet-process phosphoric acid. Hydrometallurgy, 101(1-2): 41-47.

Wang, L., Yu, Y., Liu, Y. and Long, Z., 2011. Centrifugal extraction of rare earths from wetprocess phosphoric acid. Rare Metals, 30(3): 211-215.

Weterings, K. and Janssen, J., 1985. Recovery of uranium, vanadium, yttrium and rare earths from phosphoric acid by a precipitation method. Hydrometallurgy, 15(2): 173-190.

$\mathrm{Wu}, \mathrm{Y} ., 1983$. Review of comprehesive utilization of phosphate rock-rare earth recovery. Journal of Wuhan institute of chemical industry, 1: 1-13(in Chinese).

Xu, G., 1995. Rare earth. Metallurgical Industry, Beijing, 534-538 pp.

Zhang, P., 2014. Alternative Recovery and Sustainable Development of Phosphate Resources. Procedia Engineering, 83: 37-51. 


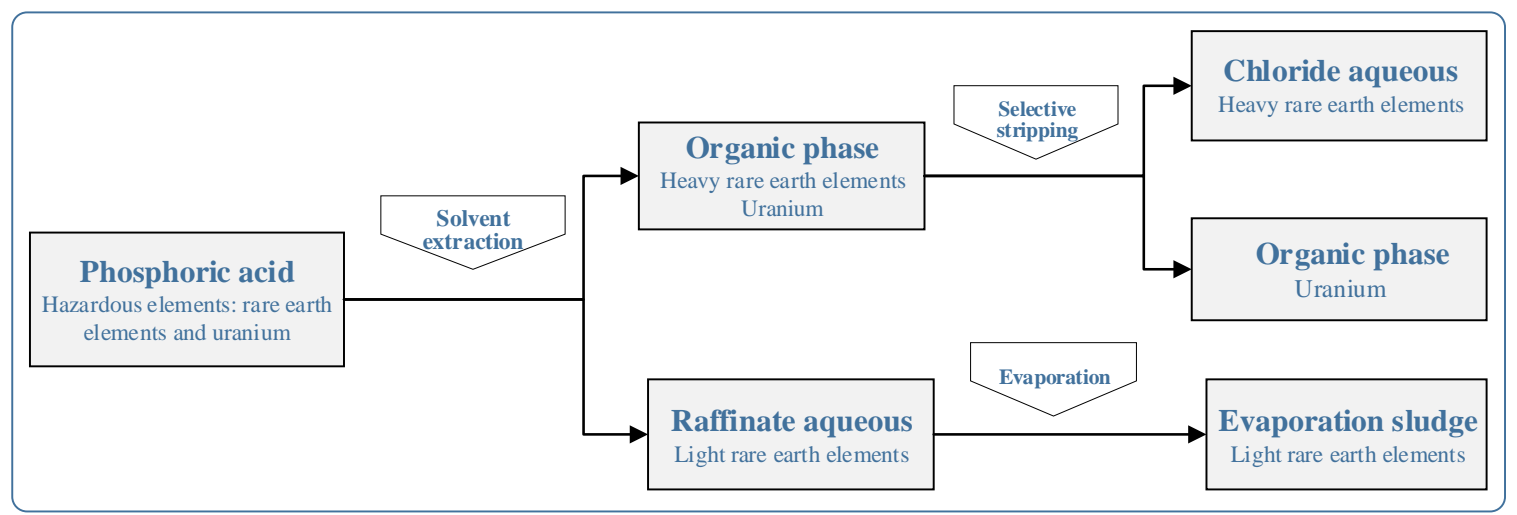

